Premature Immunosenescence in Rheumatoid Arthritis and Multiple Sclerosis Patients

Peer-reviewed author version

THEWISSEN, Marielle; LINSEN, Loes; SOMERS, Veerle; GEUSENS, Piet; RAUS, Jef \& STINISSEN, Piet (2005) Premature Immunosenescence in Rheumatoid Arthritis and Multiple Sclerosis Patients. In: ANNALS OF THE NEW YORK ACADEMY OF SCIENCES, 1051. p. 255-262.

DOI: 10.1196/annals.1361.066

Handle: http://hdl.handle.net/1942/1004 


\section{Premature immunosenescence in rheumatoid arthritis and multiple sclerosis patients}

Marielle Thewissen, Loes Linsen, Veerle Somers, Piet Geusens, Jef Raus, Piet Stinissen

Biomedisch Onderzoeksinstituut, Limburgs Universitair Centrum and School of Life

Sciences, transnational University Limburg, Universitary Campus, Diepenbeek, Belgium.

Corresponding author: Dr. P. Stinissen, Biomedisch Onderzoeksinstituut, Limburgs

Universitair Centrum, Universitary Campus, Building A, B-3590 Diepenbeek, Belgium

Tel: +32 112692 04; Fax: +32 112692 09; E-mail: piet.stinissen@luc.ac.be

Keywords: CD4+CD28 ${ }^{\text {null }} \mathrm{T}$ cells, $\mathrm{T}$ cell homeostasis, immunosenescence, multiple sclerosis, thymic involution, TREC number, rheumatoid arthritis 


\begin{abstract}
Patients suffering from $\mathrm{T}$ cell mediated autoimmune diseases (AIDs) show immune abnormalities that resemble the typical characteristics of immune dysfunction described in the elderly. In addition, the incidence of AIDs increases with advancing age. To evaluate whether rheumatoid arthritis (RA) and multiple sclerosis (MS) patients have suffered from a premature immunosenescence, we measured two indicators of aging. The number of $\mathrm{T}$ cell receptor excision circles (TRECs) and the percentage of $\mathrm{CD} 4+\mathrm{CD} 28^{\text {null }} \mathrm{T}$ cells were studied in peripheral blood mononuclear cells (PBMC) of 60 RA patients, 32 MS patients and 40 healthy controls (HC). TREC numbers were decreased in RA and MS patients as compared to age-matched HC indicating premature thymic involution. Moreover, a subset of these patients contained age-inappropriate high frequencies of CD4+CD28 ${ }^{\text {null }} \mathrm{T}$ cells. This study provides evidence of a premature senescence of the immune system in both RA and MS patients. Premature aging could be a risk factor for developing autoimmunity in genetically prone individuals in a susceptible environment.
\end{abstract}




\section{INTRODUCTION}

Autoimmune diseases (AIDs) often arise at advanced age. Patients suffering from $\mathrm{T}$ cell mediated AIDs show immune abnormalities that resemble the typical characteristics of immune dysfunction described in the elderly. Several groups have observed $\mathrm{T}$ cell clonal expansions in the peripheral blood of rheumatoid arthritis (RA) patients. ${ }^{1-4}$ Others have reported a population of T cells in RA patients with signs of replicative stress. ${ }^{2-6}$ An important aspect of immunosenescence is thymic involution. ${ }^{7}$ During thymic involution the epithelial space, where $\mathrm{T}$ cell maturation and selection takes place, is replaced by fatty tissue. This restructuring process causes a decline in the output of new T cells from the thymus. ${ }^{7}$ A space filling auto-proliferation mechanism, known as homeostatic proliferation, keeps peripheral T cell numbers at a constant level throughout life and becomes particularly important with advancing age. ${ }^{8}$ However, this mechanism will induce replicative stress on peripheral T cells. Replicatively stressed cells have lost the expression of the major costimulatory molecule CD28 which is accompanied by some phenotypic and functional changes. ${ }^{9-12}$

Premature aging, associated thymic involution and compensatory auto-proliferation could play an important role in the pathogenesis of autoimmunity. It has been shown in mice that severe $\mathrm{T}$ cell depletion or the transfer of small numbers of $\mathrm{T}$ cells into $\mathrm{T}$ cell deficient hosts induces immunopathology and the development of AIDs. ${ }^{13,14}$ Apparently, the control mechanisms that maintain a stable and diverse repertoire of naïve and memory $\mathrm{T}$ cells in a healthy functional immune system are severely compromised in lymphopenic conditions. ${ }^{15}$ In addition, lymphopenia induced auto-proliferation causes the accumulation of potential autoaggressive T cells and their functional capacities could confer an increased risk for developing autoimmunity. To evaluate whether the immune system of patients with RA or multiple sclerosis (MS) has undergone premature aging, we measured the number of $\mathrm{T}$ cell receptor excision circles (TRECs) and the percentage of CD4+CD28 ${ }^{\text {null }} \mathrm{T}$ cells in peripheral blood 
mononuclear cells (PBMC). These parameters are important indicators of aging of the immune system.

\section{MATERIALS AND METHODS}

\section{Patients and controls}

Peripheral blood samples were obtained from 40 healthy controls (HC), 60 rheumatoid arthritis (RA) and 32 clinically definite multiple sclerosis (MS) patients. All RA patients fulfilled the 1988 American College of Rheumatology criteria for RA. A summary of patient and control characteristics are enlisted in Table 1. Disease activity in RA patients was evaluated by clinical examination. Patients and controls were divided into 3 groups according to their age. The youngest age group (15-40 years) contained 16 HC, 5 RA and 17 MS patients, the middle age group (41-60 years) consisted of $14 \mathrm{HC}, 30 \mathrm{RA}$ and 14 MS patients, and the oldest group (60 years and older) contained $10 \mathrm{HC}$ and $24 \mathrm{RA}$ patients.

\section{Analysis of CD4+CD28 ${ }^{\text {null }} \mathrm{T}$ cell frequencies}

PBMC were isolated by means of Ficoll HyPaque density gradient centrifugation (Sigma, St. Louis, MO, USA). Percentages of CD4+CD28 $8^{\text {null }} \mathrm{T}$ cells were determined by flow-cytometric analysis. PBMC were stained with fluorescein isothiocyanate (FITC) labeled anti-CD4 and phycoerytrin (PE) labeled anti-CD28 antibodies (BD Biosciences, Erembodegem, Belgium). Cells were analyzed with a FACS Calibur (BD Biosciences). The percentage of CD28 ${ }^{\text {null }} \mathrm{T}$ cells within the CD4+ T cell population was then calculated.

\section{Quantification of TREC numbers}

Genomic DNA was isolated by incubating cells in lysis buffer (75 mM NaCl, 25 mM EDTA, $1 \%$ sodium dodecyl sulfate (SDS) and $50 \mu \mathrm{g} / \mathrm{ml}$ proteinase $\mathrm{K}$ ) for 1 hour at $37^{\circ} \mathrm{C}$, followed by 
chloroform:isoamylalcohol (24:1) extraction. TREC numbers in 100 ng of gDNA were measured with quantitative real-time PCR LightCycler technology (Roche Diagnostics GmbH, Mannheim, Germany). Each LightCycler run was reproduced at least once. Primers (5’-TCC CTT TCA ACC ATG CTG -3' and 5'-GGC TTG GGA TAG CTG T-3') were constructed to amplify a fragment including the $\delta$ Rec $\varphi j \alpha$ signal joint. The TREC 5' probe (5'-GGC CCT GTC TGC TCT TCA-3') was labeled at the 3' end with fluoresceine, whereas the TREC 3' probe (5'-CAC CGT TCT CAC GAG TTGp-3') was labeled at the 5' end with LightCycler Red 640. For amplicon detection, the LightCycler DNA FastStart Master Hybridization Probes kit was used according to the manufacturer's instructions (Roche Diagnostics $\mathrm{GmbH}$ ). In addition, reaction mixtures contained 100 ng gDNA, 3mM MgCl $2,0.5$ pmol primers and $0.2 \mathrm{pmol}$ probes. The PCR program consisted of an initial $10 \mathrm{~min}$ at $95^{\circ} \mathrm{C}$ for FastStart Taq activation followed by 43 cycles of repeated denaturation ( $3 \mathrm{sec}$ at $95^{\circ} \mathrm{C}$ ), annealing $\left(10 \mathrm{sec}\right.$ at $\left.59^{\circ} \mathrm{C}\right)$ and chain extension $\left(15 \mathrm{sec}\right.$ at $\left.72^{\circ} \mathrm{C}\right)$. A serial dilution of TREC containing plasmids was used as a standard for absolute quantification of TREC numbers.

\section{Statistical analysis}

Using SPSS software, one-way analysis of variance (ANOVA) was performed to compare TREC numbers and percentages of CD4+CD28 ${ }^{\text {null }} \mathrm{T}$ cells between RA patients, MS patients and HC. Tukey tests were performed as Post Hoc test. Students' T tests were used to compare different subgroups of patients and controls. A $p$ value of less then 0.05 was considered statistically significant. 


\section{RESULTS}

\section{Premature thymic involution in RA and MS patients}

Thymic output can be estimated by evaluating the TREC content in PBMC. TRECs are generated as extrachromosomal by-products during the recombination of $V(D) J$ gene segments of the T cell receptor (TCR). TRECs are stable, do not replicate and are therefore diluted with every cell division. ${ }^{16}$ The $\delta$ Rec- $\varphi J \alpha$ signal joint (sj) TREC was described to be a good measure for thymic output. ${ }^{17}$ Figure 1 shows that TREC numbers declined progressively with age in PBMC of $\mathrm{HC}$, indicating an age-dependent decrease in thymic output. Remarkably, TREC numbers in the youngest RA patients (15-40 years) were comparable to TREC numbers in the oldest HC (60 years and older) and did not decline further with age. A statistically significant lower number of TRECs was observed in RA patients as compared to HC in the age group of 41 to 60 years (Figure 1). In addition, TREC numbers in MS patients were lower as compared to age-matched healthy individuals, especially in the youngest MS patients. However, these differences were not statistically significant (Figure 1). Apparently, during the first decades of life, thymic involution had progressed at a faster rate in RA and MS patients as compared to HC.

\section{Age-independent high frequencies of CD4+CD28 ${ }^{\text {null }} \mathrm{T}$ cells in RA and MS patients}

Studies on human aging have identified the loss of CD28 expression on both CD4+ and CD8+ $\mathrm{T}$ cells as the best biological indicator of aging in the immune system. ${ }^{18}$ Surprisingly, frequencies of CD4+CD28 ${ }^{\text {null }}$ T cells did not increase with advancing age in HC (Figure 2). In the youngest age groups, no difference in the percentage of CD4+CD28 ${ }^{\text {null }} \mathrm{T}$ cells between HC, RA and MS patients could be observed. However, percentages of CD4+CD28 ${ }^{\text {null }} \mathrm{T}$ cells did increase with advancing age in RA and MS patients. In the oldest age group, RA patients had significantly more CD4+CD28 ${ }^{\text {null }} \mathrm{T}$ cells compared to age matched HC (Figure 2). For 
RA patients, no correlation could be detected between the percentage of CD4+CD28 ${ }^{\text {null }} T$ cells and gender, disease duration, rheumatoid factor (RF) status and disease status. In addition, for MS patients there was no relation between the Expanded Disability Status Score (EDSS), gender, MS subtype and the percentage of CD4+CD28 ${ }^{\text {null }} \mathrm{T}$ cells.

\section{Discussion}

Several lines of evidence suggest that T cells play an important role in the pathogenesis of RA and MS. A skewed TCR repertoire was observed in RA patients, but none of the V $\beta$ genes was found to be consistently overexpressed in all or a subgroup of RA patients., ${ }^{2,4,19}$ Although several putative autoantigens have been implicated as candidate antigens in RA (collagen, proteoglycans, heat shock proteins (HSP)) and MS (myelin components), the disease 'triggering' antigen has not been identified. ${ }^{20}$ These findings support the concept that AIDs are not caused by a single autoantigen, but may rather result from a general dysfunction of peripheral immune tolerance or homeostasis mechanisms.

In this study, TREC content and the percentage of CD4+CD28 ${ }^{\text {null }} \mathrm{T}$ cells were studied as indicators of immunosenescence. Although the sizes of the groups were often too small to obtain significant differences, the observed age-inappropriate low TREC numbers indicate that RA and MS patients suffered from a premature thymic involution. However, several biological parameters could complicate the interpretation of TREC data. ${ }^{21}$ TREC numbers can also be diluted by peripheral $\mathrm{T}$ cell proliferation. Chronic $\mathrm{T}$ cell stimulation induces an increased $\mathrm{T}$ cell turnover in RA patients, as evidenced by age-inappropriate short $\mathrm{T}$ cell telomere lengths in RA patients. ${ }^{22}$ In addition, a decreased thymic output will induce compensatory auto-proliferation, a process which will also add to TREC dilution. An ageinappropriate thymic involution and an increased peripheral $\mathrm{T}$ cell turnover will both contribute to the decreased TREC numbers observed in RA patients. These findings are in 
agreement with the results of other reports that described decreased TREC numbers in RA and MS patients. ${ }^{3,22,23}$

In addition, we observed age-inappropriate high percentages of CD4+CD28 ${ }^{\text {null }}$ T cells in RA and MS patients. Although CD4+CD28 ${ }^{\text {null }} \mathrm{T}$ cells are devoid of a major costimulatory signal, they are neither anergic nor functionally paralyzed. ${ }^{2}$ They have gained proinflammatory capacities and cytotoxic function and are resistant to apoptosis. ${ }^{5,24}$ The presence of these cells early in disease and the fact that there is no correlation with disease duration suggests that CD4+CD28 ${ }^{\text {null }} \mathrm{T}$ cells are not just a marker for $\mathrm{T}$ cell aging but may be actively involved in the pathogenic process of AIDs. Our data are in line with the findings of other research groups that reported on increased percentages of CD4+CD28 ${ }^{\text {null }}$ T cells in RA and MS patients. ${ }^{2,5,6,24-}$ 26

Besides thymic involution, several other mechanisms could have contributed to the ageinappropriate high frequencies of CD4+CD28 ${ }^{\text {null }} \mathrm{T}$ cells. A viral infection can cause massive proliferation of peripheral T cells. Normally, the majority of these newly generated effector cells are deleted at the end of the response, thereby restoring total $\mathrm{T}$ cell numbers to normal levels. However, defects in these deletion mechanisms can account for several immune abnormalities including a contracted TCR diversity and the accumulation of large numbers of clonally expanded $\mathrm{T}$ cells. These $\mathrm{T}$ cells can persist for many years and compromise immune competence. Several research groups claim that the CD4+CD28 ${ }^{\text {null }} \mathrm{T}$ cells which emerge in the elderly are indeed cytomegalovirus (CMV) specific cells. ${ }^{27,28}$ However, the TCR specificity of the CD4+CD28 ${ }^{\text {null }}$ T cells in RA and MS patients has yet to be determined.

The decline in immunocompetence with age is accompanied by a steadily increasing incidence rate of AIDs. $^{29}$ A reduced thymic output will induce compensatory autoproliferation. This process can lead to a premature senescence of $\mathrm{T}$ cells and contribute to the immune abnormalities associated with autoimmunity and aging. Although the incidence of 
AIDs increases with advancing age, immunosenescence is clearly not sufficient to induce autoimmunity. This illustrates that autoimmunity is a complex multifactorial disorder. Premature aging could be a risk factor for developing autoimmunity in genetically prone individuals in a susceptible environment. 


\section{REFERENCES}

1. Wagner, U.G. et al. 1998. Perturbation of the T cell repertoire in rheumatoid arthritis. Proc. Natl. Acad. Sci. U. S. A 95: 14447-14452.

2. Schmidt, D. et al. 1996. CD4+ CD7- CD28- T Cells Are Expanded in Rheumatoid Arthritis and Are Characterized by Autoreactivity. J. Clin. Invest 97: 2027-2037.

3. Ponchel, F. et al. 2002. Dysregulated lymphocyte proliferation and differentiation in patients with rheumatoid arthritis. Blood 100: 4550-4556.

4. Bakakos, P. et al. 2002. Simultaneous analysis of $\mathrm{T}$ cell clonality and cytokine production in rheumatoid arthritis using three-colour flow cytometry. Clin. Exp. Immunol. 129: 370-378.

5. Fasth, A.E. et al. 2004. CD28CD4 T cells--characterization of an effector memory T-cell population in patients with rheumatoid arthritis. Scand. J. Immunol. 60: 199-208.

6. Wagner, U. et al. 2003. Clonally expanded CD4+CD28null $\mathrm{T}$ cells in rheumatoid arthritis use distinct combinations of T cell receptor BV and BJ elements. Eur. J. Immunol. 33: 79-84.

7. Linton, P.J. \& Dorshkind, K. 2004. Age-related changes in lymphocyte development and function. Nat. Immunol. 5: 133-139.

8. Goldrath, A.W. 2002. Maintaining the status quo: T-cell homeostasis. Microbes. Infect. 4: 539-545.

9. Warrington, K.J. et al. 2001. CD4+,CD28- T cells in rheumatoid arthritis patients combine features of the innate and adaptive immune systems. Arthritis Rheum. 44: 13-20.

10. Groh, V. et al. 2003. Stimulation of T cell autoreactivity by anomalous expression of NKG2D and its MIC ligands in rheumatoid arthritis. Proc. Natl. Acad. Sci. U. S A 100: 9452-9457.

11. Yen, J.H. et al. 2001. Major histocompatibility complex class I-recognizing receptors are disease risk genes in rheumatoid arthritis. J. Exp. Med. 193: 1159-1167.

12. Snyder, M.R. et al. 2002. Formation of the killer Ig-like receptor repertoire on CD4+CD28null T cells. J. Immunol. 168: 3839-3846. 
13. Bell, E.B. et al. 1987. The stable and permanent expansion of functional T lymphocytes in athymic nude rats after a single injection of mature T cells. J. Immunol. 139: 1379-1384.

14. Gleeson, P.A. et al. 1996. Organ-specific autoimmunity induced by lymphopenia. Immunol. Rev. 149: 97-125.

15. Barthlott, T. et al. 2003. T cell regulation as a side effect of homeostasis and competition. J. Exp. Med. 197: 451-460.

16. Douek, D.C. et al. 1998. Changes in thymic function with age and during the treatment of HIV infection. Nature 396: 690-695.

17. Hazenberg, M.D. et al. 2001. T cell receptor excision circles as markers for recent thymic emigrants: basic aspects, technical approach, and guidelines for interpretation. J. Mol. Med. 79: 631-640.

18. Vallejo, A.N. et al. 2004. T-cell senescence: a culprit of immune abnormalities in chronic inflammation and persistent infection. Trends Mol. Med. 10: 119-124.

19. VanderBorght, A. et al. 2000. Skewed T-cell receptor variable gene usage in the synovium of early and chronic rheumatoid arthritis patients and persistence of clonally expanded $\mathrm{T}$ cells in a chronic patient. Rheumatology. (Oxford) 39: 1189-1201.

20. Firestein, G.S. 2003. Evolving concepts of rheumatoid arthritis. Nature 423: 356-361.

21. Hazenberg, M.D. et al. 2003. Thymic output: a bad TREC record. Nat. Immunol. 4: 97-99.

22. Koetz, K. et al. 2000. T cell homeostasis in patients with rheumatoid arthritis. Proc. Natl. Acad. Sci. U. S. A 97: 9203-9208.

23. Hug, A. et al. 2003. Thymic export function and $\mathrm{T}$ cell homeostasis in patients with relapsing remitting multiple sclerosis. J. Immunol. 171: 432-437.

24. Markovic-Plese, S. et al. 2001. CD4+CD28- costimulation-independent T cells in multiple sclerosis. J. Clin. Invest 108: 1185-1194. 
25. Gerli, R. et al. 2004. CD4+CD28- T lymphocytes contribute to early atherosclerotic damage in rheumatoid arthritis patients. Circulation 109: 2744-2748.

26. Pawlik, A. et al. 2003. The expansion of CD4+CD28- T cells in patients with rheumatoid arthritis. Arthritis Res. Ther. 5: R210-R213.

27. van Leeuwen, E.M. et al. 2004. Emergence of a CD4+CD28- Granzyme B+, Cytomegalovirus-Specific $\mathrm{T}$ Cell Subset after Recovery of Primary Cytomegalovirus Infection. J. Immunol. 173: 1834-1841.

28. Ouyang, Q. et al. 2004. Dysfunctional CMV-specific CD8(+) T cells accumulate in the elderly. Exp. Gerontol. 39: 607-613.

29. Weyand, C.M. et al. 2003. Immunosenescence, autoimmunity, and rheumatoid arthritis. Exp. Gerontol. 38: 833-841. 
Table 1 Patient and control characteristics

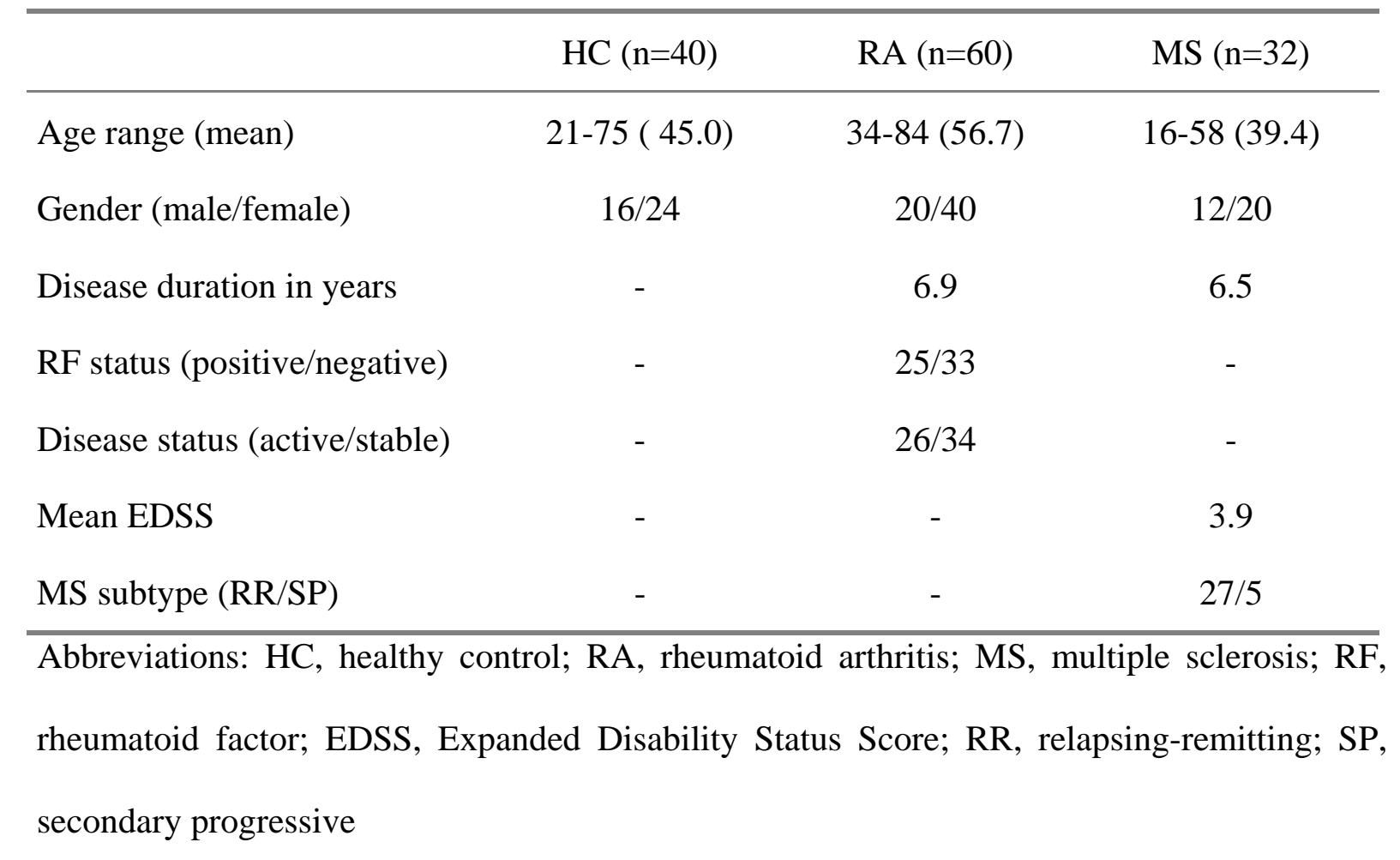




\section{Figure legends}

Figure 1: TREC numbers in RA patients, MS patients and HC. Patients and HC were divided into three age-groups. The average number of TRECs in $100 \mathrm{ng}$ of gDNA was determined for all subgroups. Error bars illustrate SEM. Numbers on top of SEM indicate the number of patients or controls tested in the corresponding group. ${ }^{*} p<0.05$

TREC, T cell receptor excision circle; RA, rheumatoid arthritis; MS, multiple sclerosis ; HC, healthy control ; gDNA, genomic DNA ; SEM, standard error of the mean

Figure 2: Percentages of CD4+CD28 ${ }^{\text {null }} \mathrm{T}$ cells in RA patients, MS patients and HC. The average percentage of CD4+CD28 $8^{\text {null }} \mathrm{T}$ cells was determined for all subgroups. Error bars illustrate SEM. Numbers on top of SEM indicate the number of patients or controls tested in the corresponding group. ${ }^{*} p<0.05$

RA, rheumatoid arthritis; MS, multiple sclerosis ; HC, healthy control ; SEM, standard error of the mean 
Figure 1

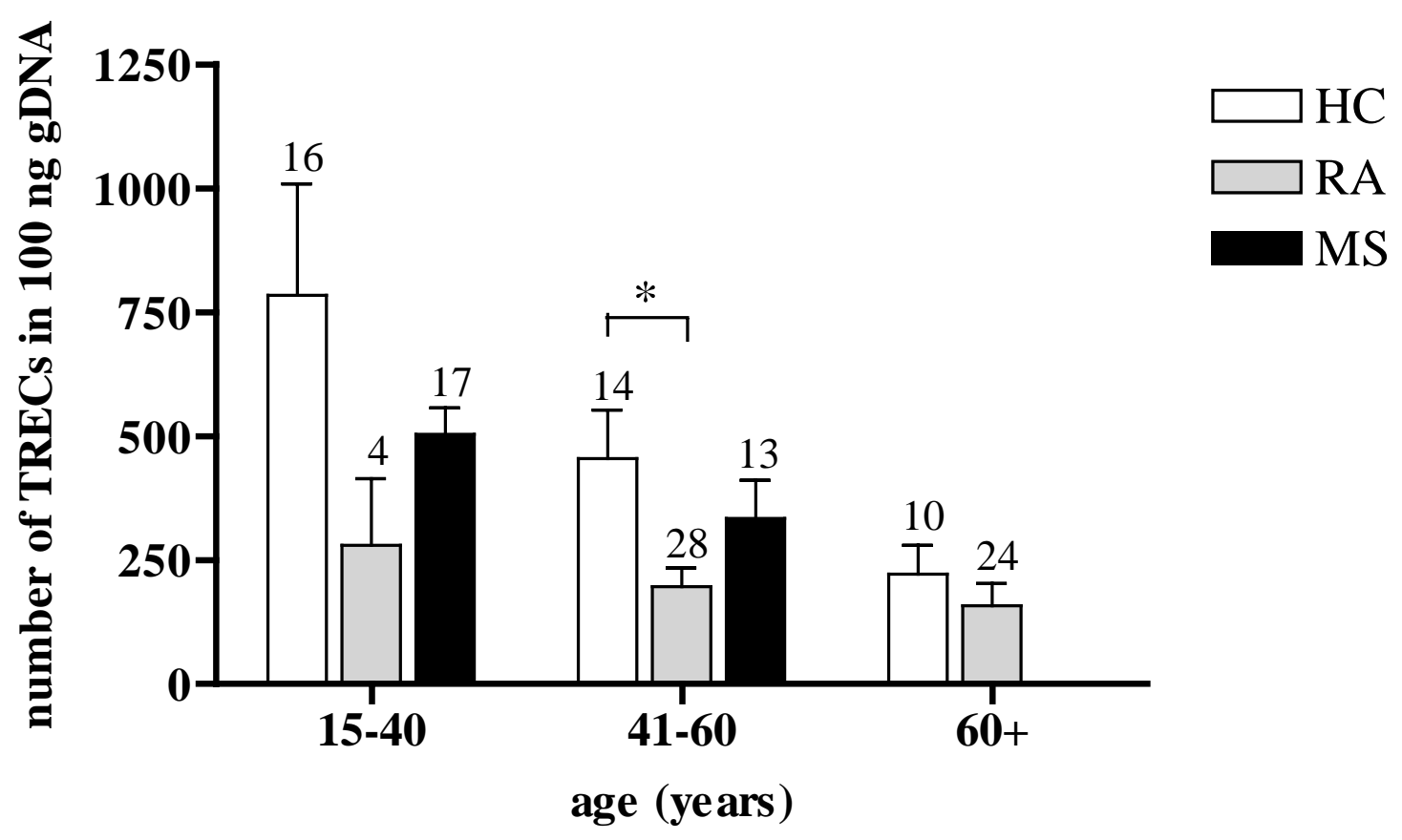


Figure 2

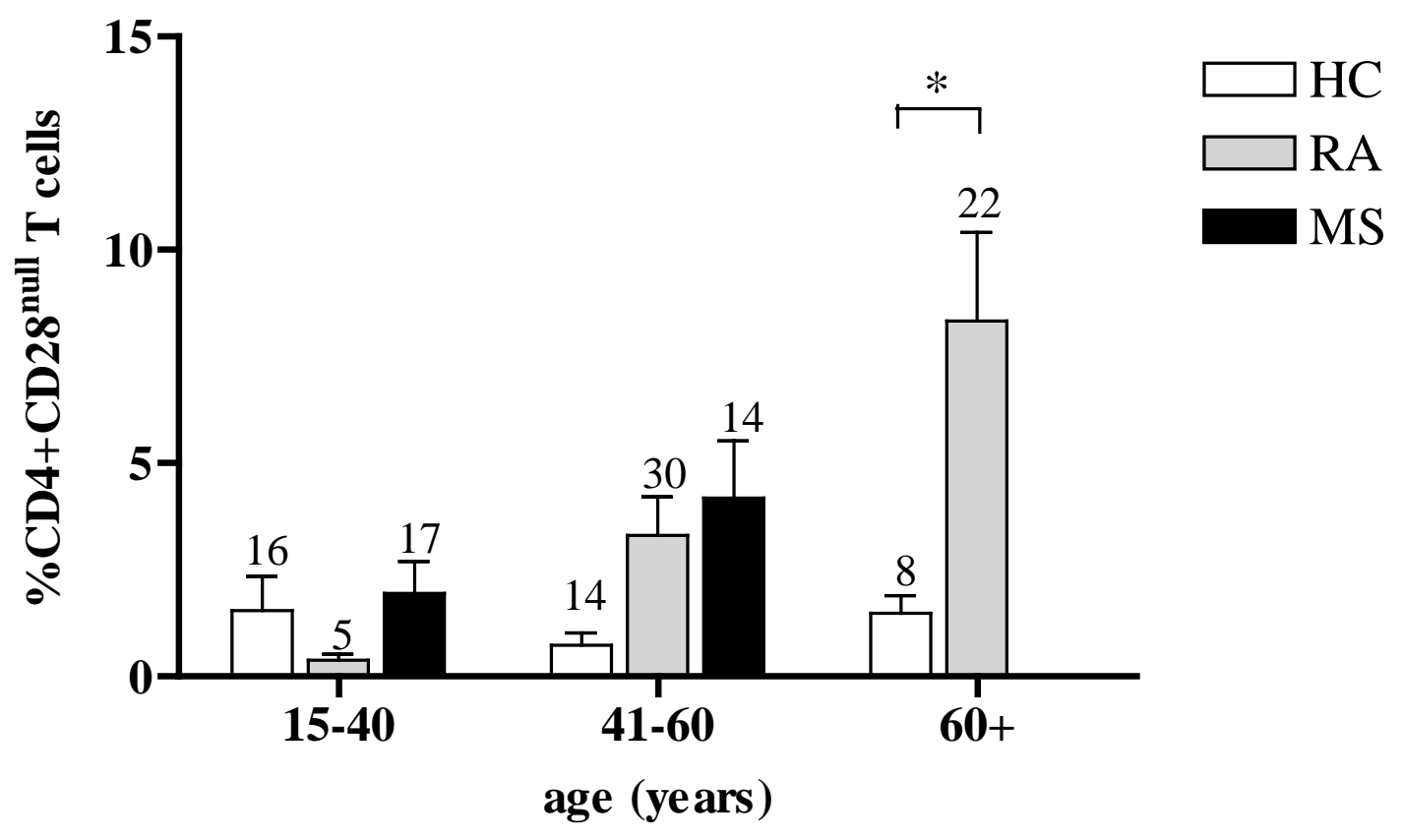

